
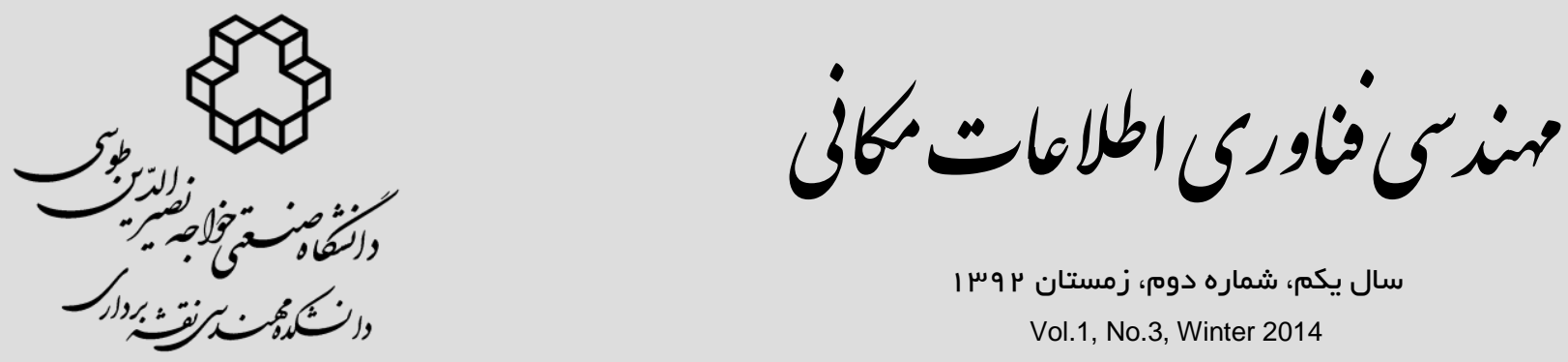

سال يكم، شماره دوهم، زمستان ب وس

Vol.1, No.3, Winter 2014

ييشنهاد روشى جديد در آناليز جابهجايى شبكههاى ارتفاعى

\author{
غلامرضا رضايى جاويد'، مسعود مشهدى حسينعلى

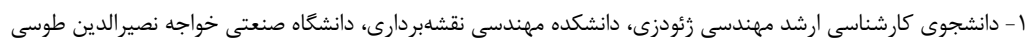

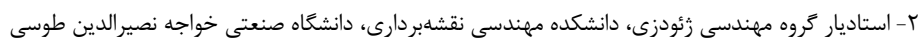

تاريخ دريافت مقاله:

جكيده

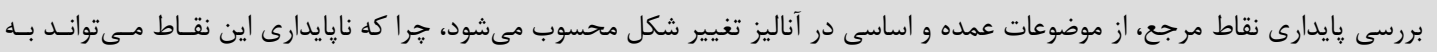

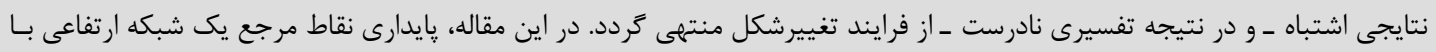

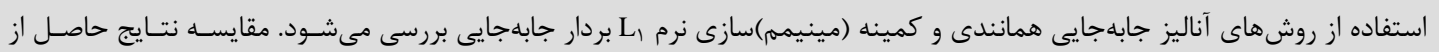

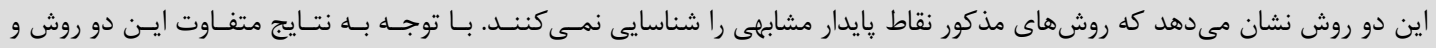

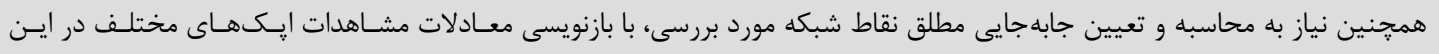

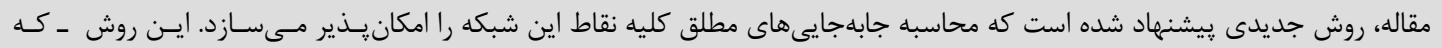
روش ايكمرجع ناميده مىشود - جابهجايى نقاط شبكهاى ارتفاعى را نسبت به وضعيت مرجع يا اوليه شبكه مورد نظر به دست مى دهديد. كليدوازهها: آناليز تغيير شكل، روش همانندى، روش مينيمهسازى نرم Lا بردار جابهجايى، روش إيكمرجع. 
سيستم مختصات در روشهـاى هندسـى آنـاليز تغييـر

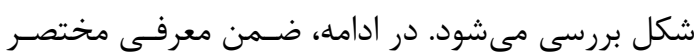

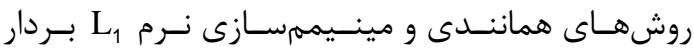
جابـهـهـايى، نتـايج حاصـل از ايــن دو روش در آنـاليز جابهجايى سازههاى اين نيروگًاه مقايسه مسى گردنـد. در

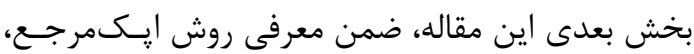
نتايج حاصل از اين روش در شبكه مذكور ارائه مىشود.

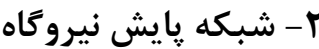

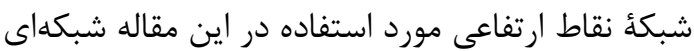

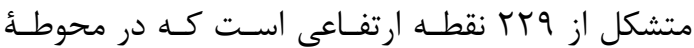

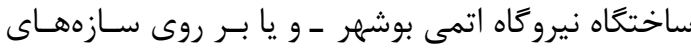

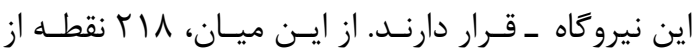
نقاط اين شبكه بر روى گروهى از سازههاى اين نيروگاه

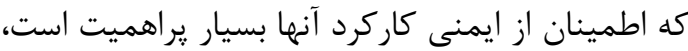

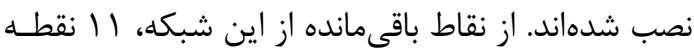
در محوطة اين نيرو Fاه ساختمانسازى مسى شــوند و بــهـ لحاظ تيب ساخت در گروه بنج مارك هاى عمقـى قـرار

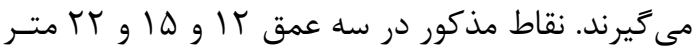
ساختمانسازى مى مئردند.

اين شبكه را در بيش از V إيك، متخصصان ايرانى و ييمانكار يروزة تكميل اين نيروگاه اندازهزيرى كردهانـد.

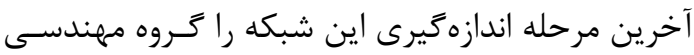

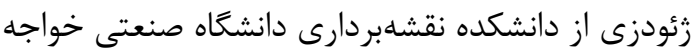
نصيرالدين طوسى ـ و با فاصله زمانى ^ سال از آخــرين

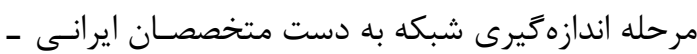

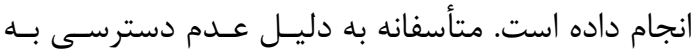
مشاهدات اندازهخيرىهاى انجـام شـده يِيمانكـارِ يـروزة

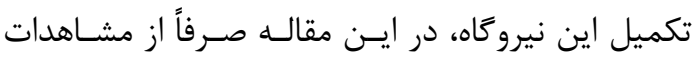

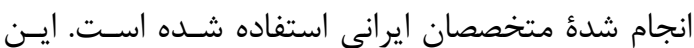
اندازهزيرىها شامل جهــار مرحلـه مشـاهدات ترازيـابى

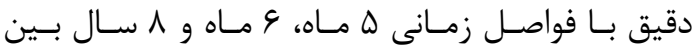
ايكهاى مذكور است.
|- مقدمه

در روشهاى هندسى آنـاليز تغييـر شـكل، شـبكههـاى

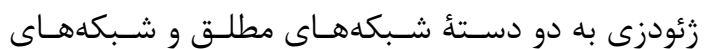
نسبى تقسيمبندى مى شوند. در شبكههاى مطلق، برخى از نقاط شبكه يا خارج از حوزه تغيير شكل قرار دارند، و يا اينكه خارج از اين حوزه فرض مىشوند. از اين نقـاط لئ

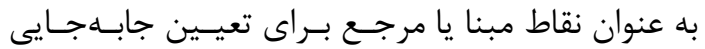

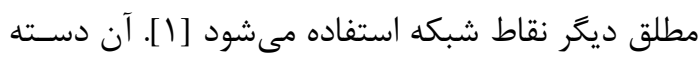
از شبكههاى زئودتيكى را كه تمامى نقاط آنهـا در حــوزه

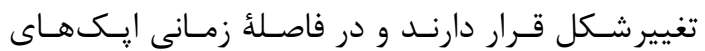
اندازهخيرى مورد نظر ثابت نمى مانند، شبكههاى نسـبى

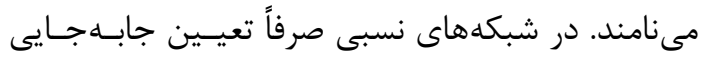
نسبى نقاط شبكه امكانيذير است.

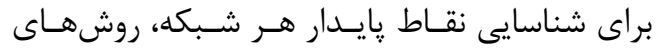

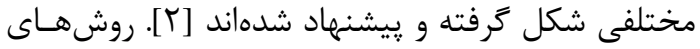

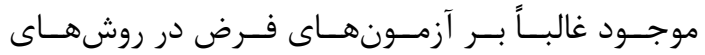
يارامتريك آمـار رياضسى مبتنـى انـد و ماهيـت فيزيكىى

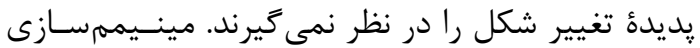

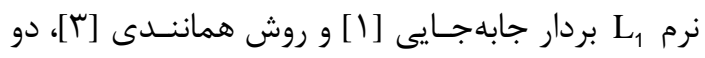

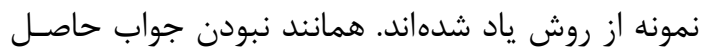
از روشهاى آمارى مختلف، تعيـين جابـهـهــيى مطلـق ئق نقاط شبكه يايش تغيير شكل را با جالشى جدى مواجه

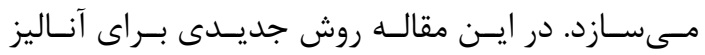
جابهجايى نقاط شبكههاى رفتارسنجى ارتفاعى ييشنهاد

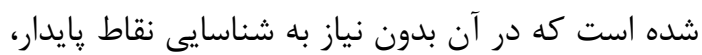
جابه جايى مطلق نقاط شبكه را مى توان محاسـبه كـرد.

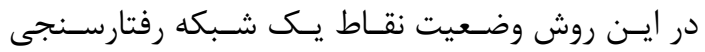

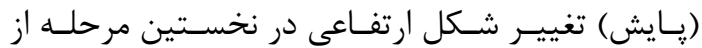
اندازهخيرى آن به عنوان وضعيت وضعيت مرجع شــبكه لئه انتخاب مىشود و جابهجايى تمامى نقاط شبكه، با توجه به اين وضعيت محاسبه و تعيين مى گردد. بـدين لحساظ

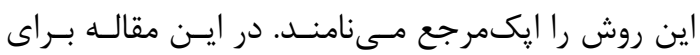
معرفى روش ياد شده، شبكٔ يايش تغيير شكل ارتفاعى رونى سازههاى نيرو گاه اتمى بوشهر مورد استفاده قرار گرفتـهـ است. براى اين منظور و در نخستين بخش از اين مقاله، 
$\mathbf{C}_{j}=\mathbf{T C}_{i} \mathbf{T}^{\mathrm{T}}$

رابطه (广)

ب-1 آز آزمون همانندى

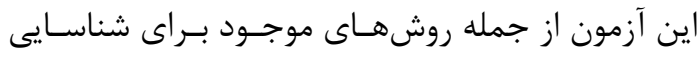

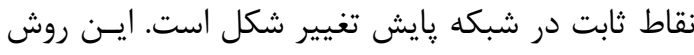

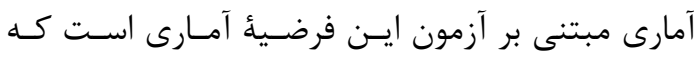

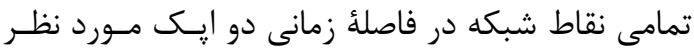

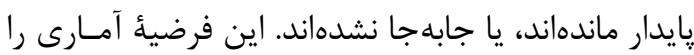

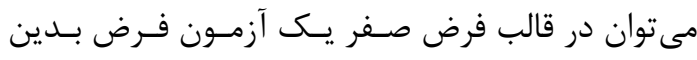

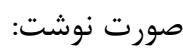
رابطه (ץ-الف)

$\mathrm{H}_{\circ}: \mathrm{E}\left\{\hat{\mathbf{x}}_{1}\right\}-\mathrm{E}\left\{\hat{\mathbf{x}}_{2}\right\}=\mathrm{E}\{\hat{\mathbf{d}}\}=0$

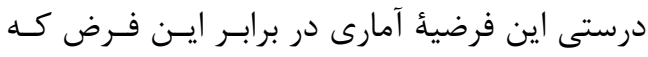

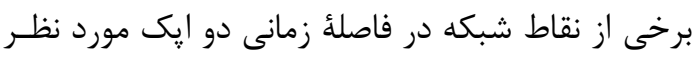

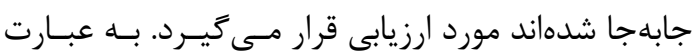
ديكر، فرض مخالف يا فرض مقابل به كار رفتـه در ايـن آزمون بدين صورت است:

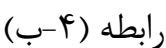

$\mathrm{H}_{\mathrm{a}}: \mathrm{E}\left\{\hat{\mathbf{x}}_{1}\right\}-\mathrm{E}\left\{\hat{\mathbf{x}}_{2}\right\}=\mathrm{E}\{\hat{\mathbf{d}}\} \neq 0$

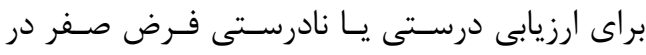
آزمون مورد بحث، از اين آماره استفاده مىشود:

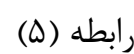

$\omega=\frac{\hat{\mathbf{d}}^{\mathrm{T}} \mathbf{Q}_{\mathrm{d}}^{+} \hat{\mathbf{d}}}{\mathrm{h} \hat{\sigma}_{0}^{2}} \sim \mathrm{F}_{\alpha, \mathrm{h}, \mathrm{df}}, \quad \Omega=\hat{\mathbf{d}}^{\mathrm{T}} \mathbf{Q}_{\mathbf{d}}^{+} \hat{\mathbf{d}}$

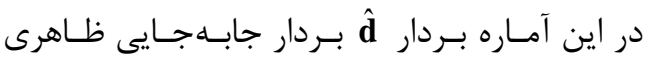

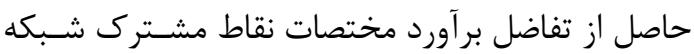
در دو إيك اندازمخيرى مورد نظــر (

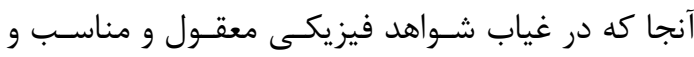

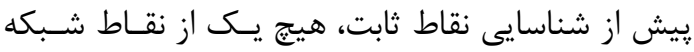

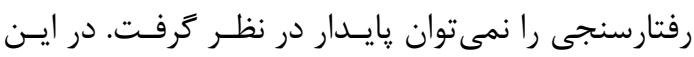

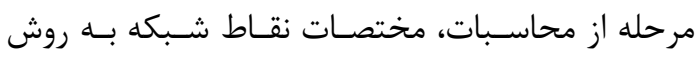
سرشكنى قيود داخلى و با مقادير اوليـهُ مشـابهى بـراى

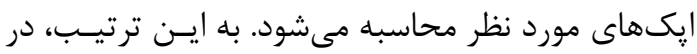

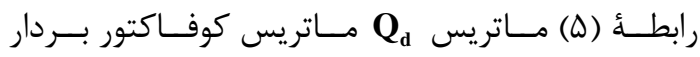

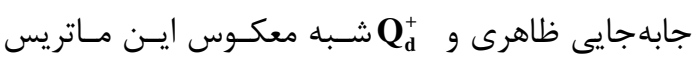

\section{r- نقش ديتوم در تعيين جابه جايى مطلــق نقــاط

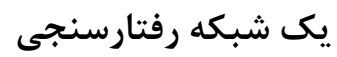

مختصات نقاط شبكه، به ديتوم مورد استفاده در فرايند

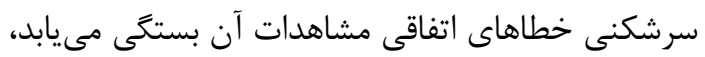

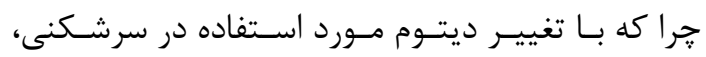

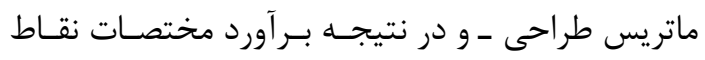

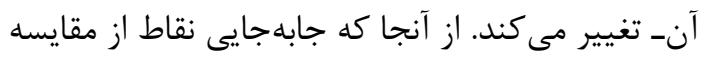
مختصات حاصل از سرشكنى خطاهاى اتفاقى مشاهدات

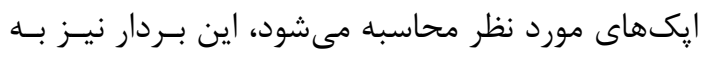

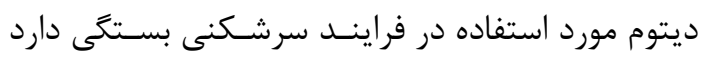

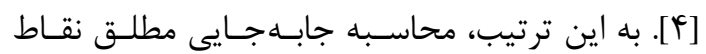
شبكه، مستلزم شناسايى مجموعه نقـاطى اسـت كـهـ در

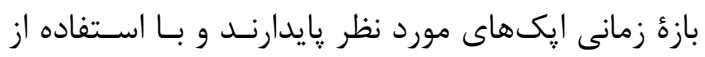

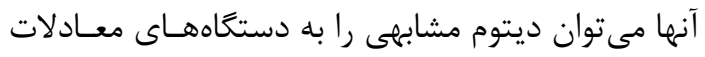

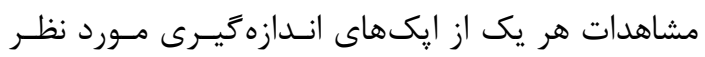

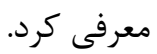

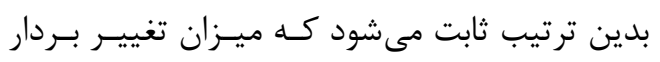
جابهجايى بر اثر تغيير ديتوم مورد استفاده در سرشكنى

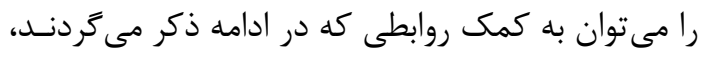
محاسبه كرد [ب]: رابطه (1)

\section{$\mathbf{T}=\mathbf{I}-\mathbf{s}\left(\mathbf{r}^{T} \mathbf{s}\right)^{-1} \mathbf{r}^{T}$}

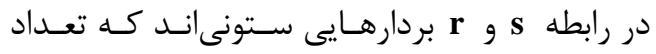

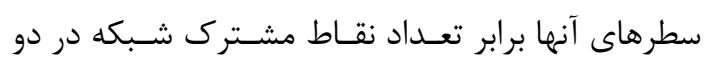

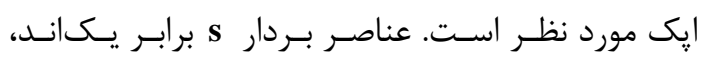

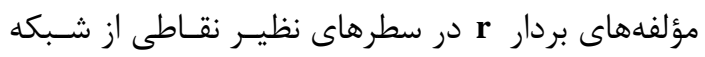

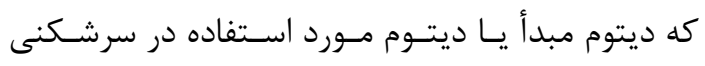

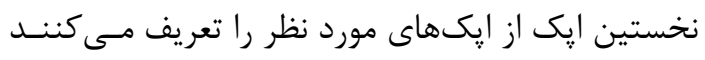

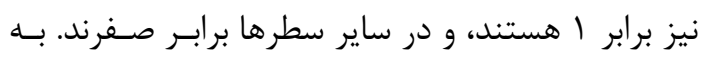
اين ترتيب، بردار جابهجايى و ماتريس كوواريانس آن در انتقال از ديتوم مبدأ ـ يا ديتومى كه تعيين جابهجايى نسبت بــ (C)

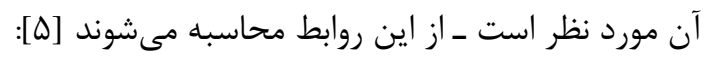

$\mathbf{d}_{j}=\mathbf{T d}_{i}$

رابطه (r) 
إيك اندازهَيرى جابه جا شده اسـت منظـور مسى گَردد.

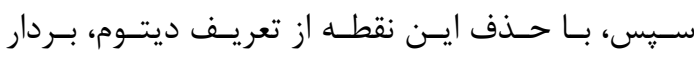
جابهجايى نقاط و ماتريس كوفاكتور آنهـا بــا اسـتفاده از روش انتقال متشابه (روابط ا، Y و ؟) در ديتوم جديدى كه با نقاط باقىمانده تعريف مى گردد، محاسبه مى مى مود.

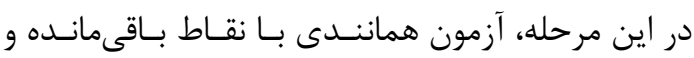

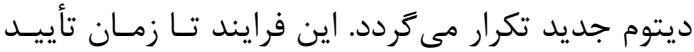

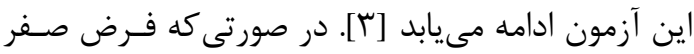

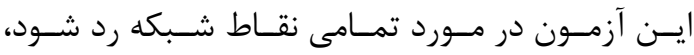
مشخص خواهد شد كه شبكه مورد نظر شبكهاى نسبى است و محاسـبـه جابـهـهـايى مطلـق نقـاط ايـن شـبكه امكان يذير نخواهد بود. بهمنظور اطمينان از عدم ارتكاب

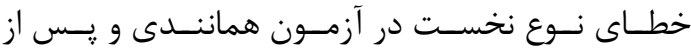
شناسايى كليه نقاط ثابت شبكه در صورت وجود، نقـاط ثابت مشترك بين دو إيك در آزمون فرضى كه در ادامه

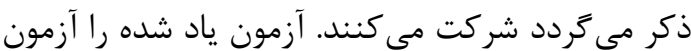
نقطه منفرد' مى نامند [r]:

$$
\begin{aligned}
& \text { H。 } \\
& \mathrm{H}_{\mathrm{a}}: \mathrm{E}\left(\mathrm{d}_{\mathrm{j}}\right)^{\mathrm{I}} \neq 0 \\
& \text { رابطه (•-1 (ابط) }
\end{aligned}
$$$$
\text { آماره آزمون از طريق اين رابطه تعريف مى گردد: }
$$

رابطه (1)

$\omega_{\mathrm{j}}=\frac{\hat{\mathbf{d}}_{\mathbf{j}}^{\mathbf{T}} \mathbf{Q}_{\mathbf{d}_{\mathbf{j}}^{+}} \hat{\mathbf{d}}_{\mathbf{j}}}{\mathrm{k} \hat{\sigma}^{2}} \sim \mathrm{F}_{\alpha, \mathrm{k}, \mathrm{df}}$

اخر

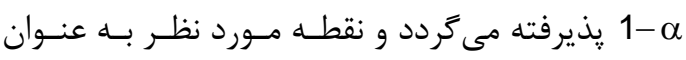

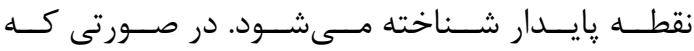
باشد، فرض صفر رد مى گردد و نقطه مورد $\omega_{j}>F_{\alpha, k, d f}$

نظر نايايدار در نظر گرفته مىشود[ب].

r-r - روش مينيممسازى نرم اL بردار جابه جايى

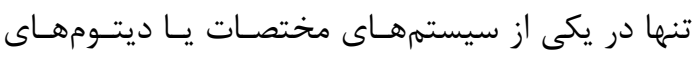

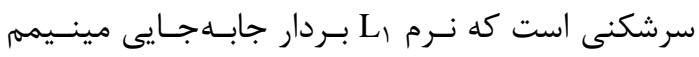

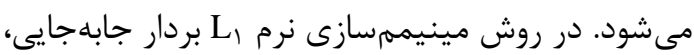

1. Single point hypothesis test

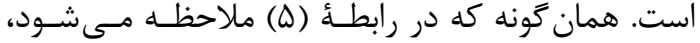

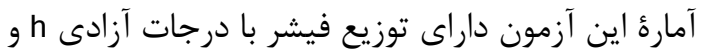

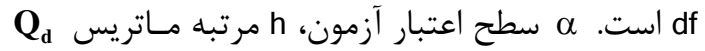

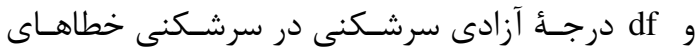

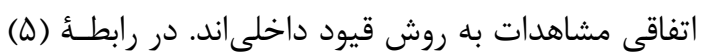

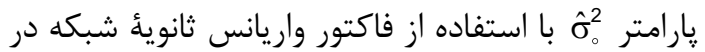
سرشكنى خطاهاى مشاهدات دو ايك مورد نظر ( ) و با استفاده از اين رابطه محاسبه مى شود:

) رابطه (c)

$\hat{\sigma}_{o}^{2}=\left(r_{k} \hat{\sigma}_{o k}^{2}+r_{k+1} \hat{\sigma}_{\mathrm{k}+1}^{2}\right) / r$

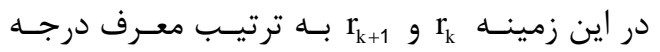

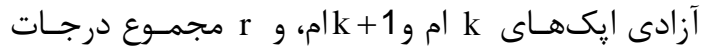
آزادى دو إيك مورد نظر است.

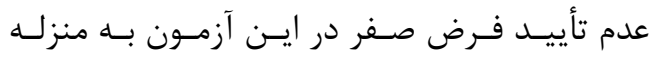
جابهجايى دست كم يكى از نقاط شبكه در بازه زمانى دو ايك مورد نظر است. در اين صورت، كام بعـدى در ايسن

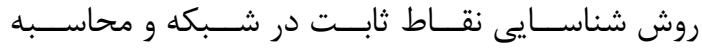
جابهجايى ديخر نقاط نسبت به نقاط ثابت شـبكه اسـت. در اين روش براى شناسايى نقاط يايدار از سهمم هر يك از نقاط شبكه در آماره اين آزمون استفاده مىشـود. بــهـ

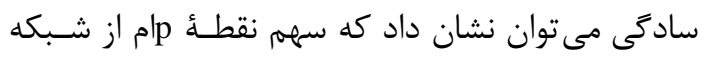

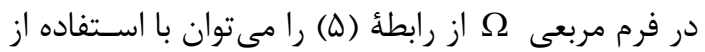
اين روابط ـ كه در يى مى آيند ـ محاسبه كرد:

(V) رابطه

$\mathbf{d}=\left[\begin{array}{l}\mathbf{d}_{\mathrm{r}} \\ \mathbf{d}_{\mathrm{p}}\end{array}\right], \mathbf{Q}_{\mathbf{d}}^{+}=\left[\begin{array}{cc}\mathbf{W}_{\mathrm{r}} & \mathbf{W}_{\mathrm{rp}} \\ \mathbf{W}_{\mathrm{pr}} & \mathbf{W}_{\mathrm{p}}\end{array}\right]$

(1) رابطه

$d_{j}^{\prime}=w_{j}^{-1} w_{j r} d_{r}+d_{j}$

(9)

$\Omega_{\mathrm{j}}=\mathbf{d}_{\mathbf{j}}^{\prime \mathbf{T}} \mathbf{w}_{\mathbf{j}} \mathbf{d}_{\mathbf{j}}^{\prime}$

بعد از محاسبه سهم جابهجــايى هــر نقطـهـ در فـرم مربعى مذكور، نقطهُ داراى بيشترين سـهم در ايسن فـرم

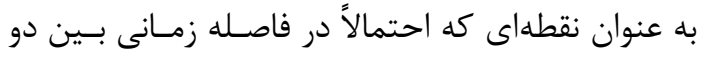




\section{F - آناليز جابه جايى به روش إيك مرجع}

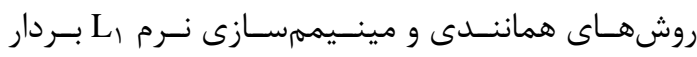

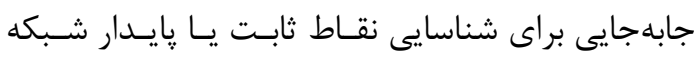

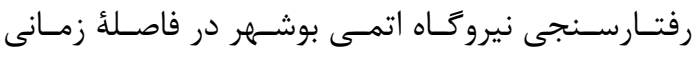

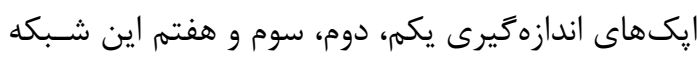

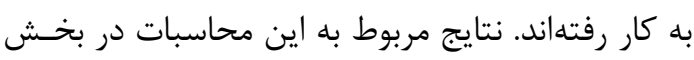

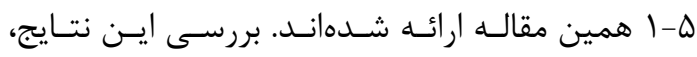

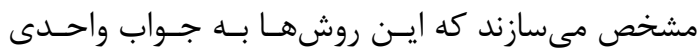

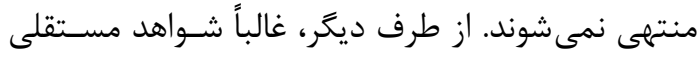

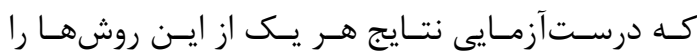

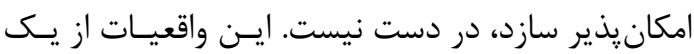

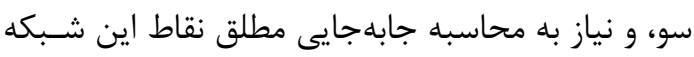

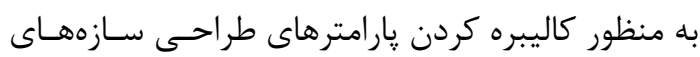

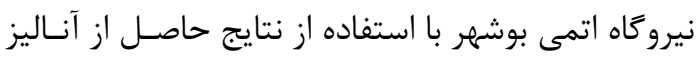

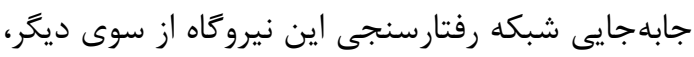

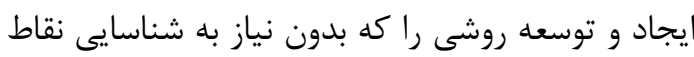
ثابت محاسبه جابهجايى مطلـق نقــاط شـبكه را ممكـن

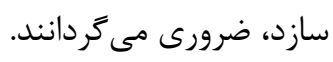

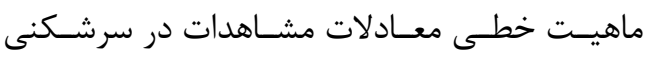

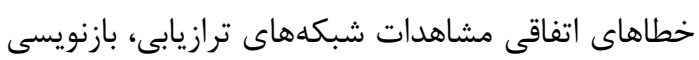

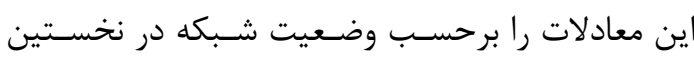

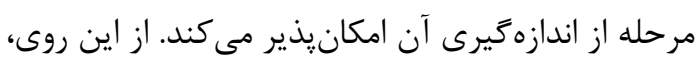

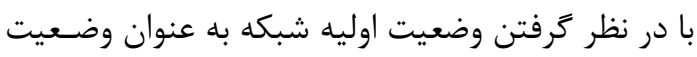

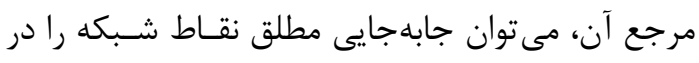

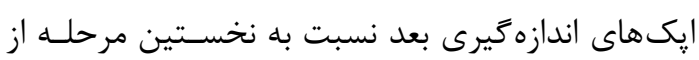

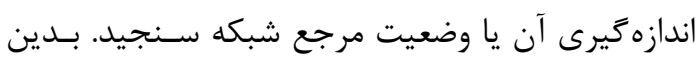

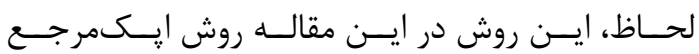

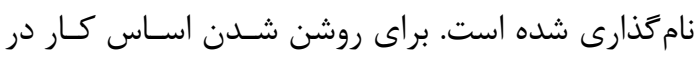

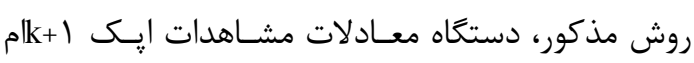

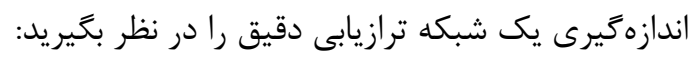

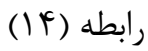

$\mathrm{h}_{\mathrm{j}}^{\mathrm{k}+1}-\mathrm{h}_{\mathrm{i}}^{\mathrm{k}+1}=\Delta \mathrm{h}_{\mathrm{ij}}^{\mathrm{k}+1}+\mathrm{v}_{\mathrm{ij}}^{\mathrm{k}+1}$

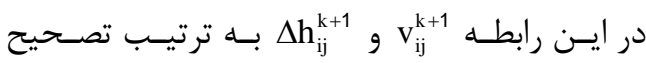

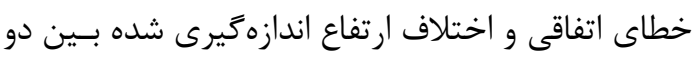

اين ديتوم خـاص بــراى شناسـايى نقـاط ثابـت در يـــ

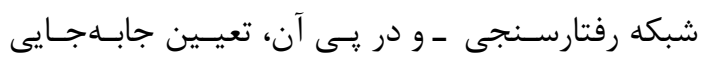

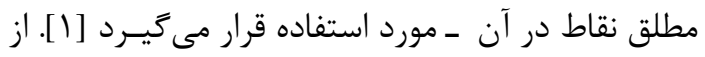

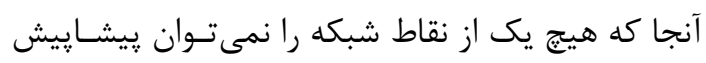

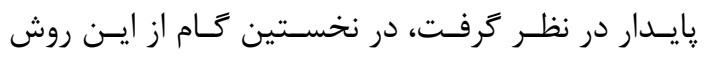

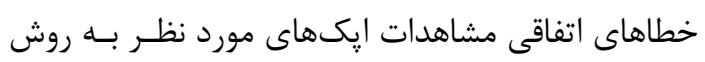

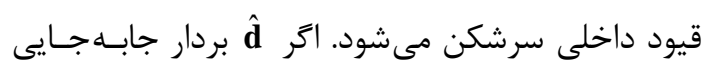

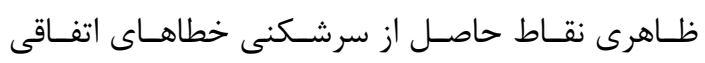

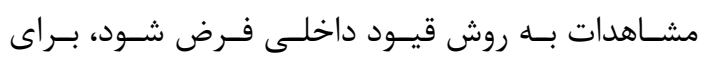

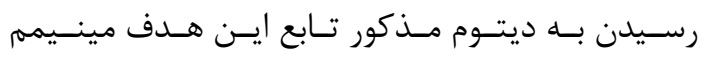
مى تردد [1]: مبدن $\varphi=\|\mathbf{d}\|_{1} \rightarrow \min \quad$ (I ) (IT)

با توجه به تأثير ديتوم مورد اسـتفاده در سرشـكنى

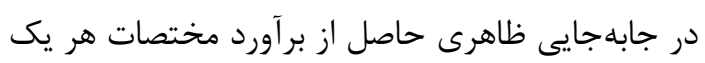

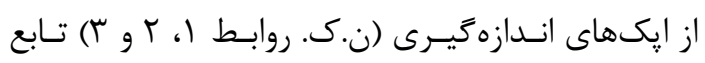

هدف ياد شده را مىتوان بدين صورت بازنويسى كرد: رابطه (IT)

$\varphi=\|\mathbf{d}-\mathbf{s} t\| \rightarrow$ Min, $\quad \mathrm{t}=\left(\mathbf{r}^{\mathrm{T}} \mathbf{s}\right)^{-1} \mathbf{r}^{\mathrm{T}} \mathbf{d}$

در اين عبارت، اسكالر t جنان تعيين مسىشـود كـهـ

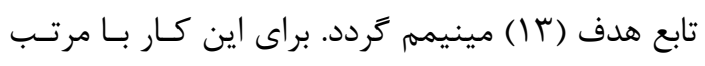

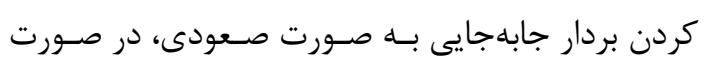

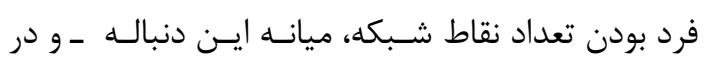

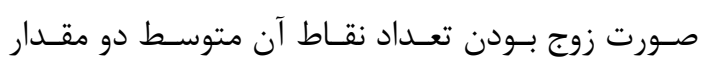

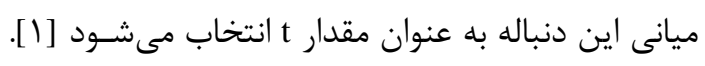

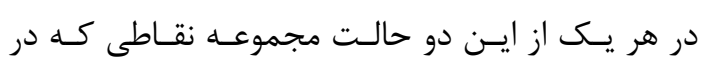

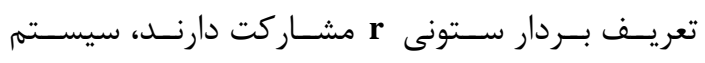

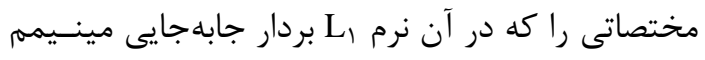

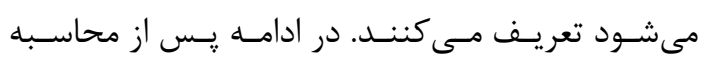

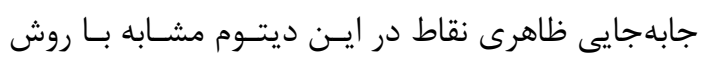

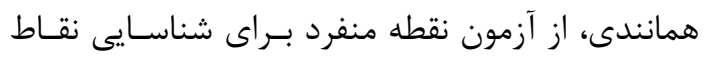

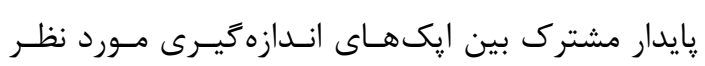

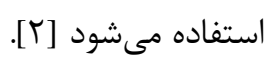


برطرف سازد. با اين حال، اين روش لزوماً تنهـا راهحـلـ

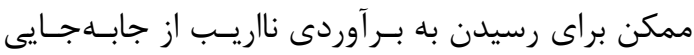

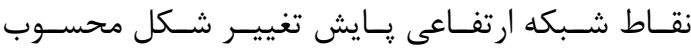
نمىشود، زيرا با معرفى بردار انتقال ثابت c بـه دسـتـاه

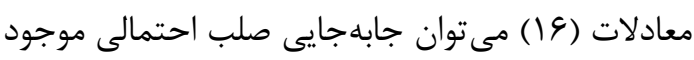
را به همراه فاصلئ اطمينان مربوط به آن آن محاسبه كـرد. به عبارت ديخر، دستخاه معادلات (9) را را مى توان بـدين

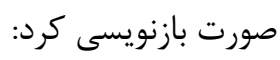

$d_{j}-d_{i}+c=\delta \Delta h_{i j}^{k, k+1}+v_{i j}^{k+1} \quad(ا ل ف|l| l)$ $\delta \Delta h_{i j}^{k, k+1}=\Delta h_{i j}^{k+1}-\left(h_{j}^{k}-h_{i}^{k}\right) \quad(ب-\mid \Lambda)(ر ا ب ط$

جابهجـايىهـاى حاصـل از دسـتَاه معـادلات (1) تحت تأثير جابهجايى احتمالى صلب شبكه نخواهد بود.

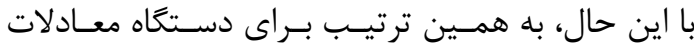

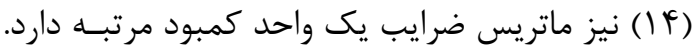
با فرض كوجك بودن جابهجايى نقاط در فاصـلة زمـانى دو ايك اندازهيرى مورد نظر، مسير حركت نقاط شبكه

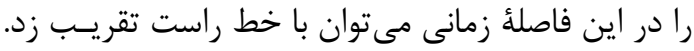

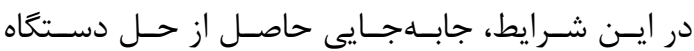

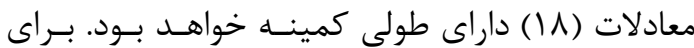

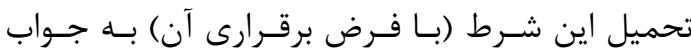

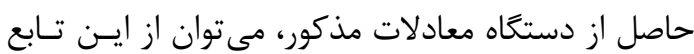

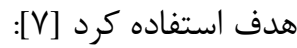

$\varphi=\mathbf{v}^{T} \mathbf{P} \mathbf{v}+\mathbf{d}^{T} \mathbf{W d} \rightarrow \min$

رابطه (19)

در ايسن رابطــه، P مـاتريس وزن شــبهمشـاهدات ماتر يسى قطــى اسـت كـه عناصـر آن

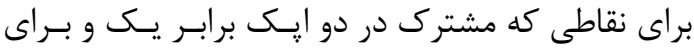

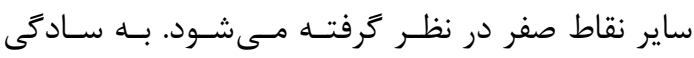

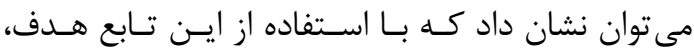
برآورد كمترين مربعات بـردار جابـهـــايى نقــاط، بــردار

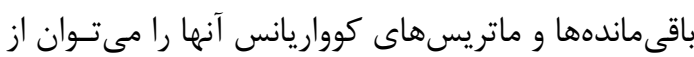
طريق روابطى كه در بيى مى آيند محاسبه كرد [^]ـ:

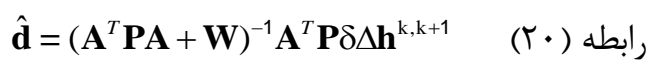

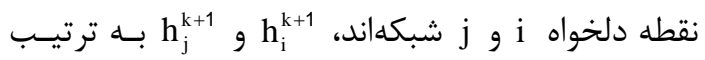

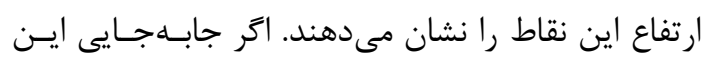

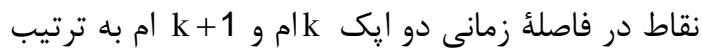

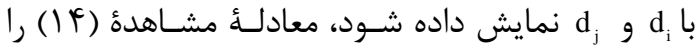
مى توان بدين صورت بازنويسى كرد: رابطه (ه)

$\left(h_{j}^{k}+d_{j}\right)-\left(h_{i}^{k}+d_{i}\right)=\Delta h_{i j}^{k+1}+v_{i j}^{k+1}$

رابطه (ها) را به اين صورت مىتوان بازنويسى كرد: $d_{j}-d_{i}=\delta \Delta h_{i j}^{k, k+1}+v_{i j}^{k+1} \quad$ رابطه (1) $\delta \Delta \mathrm{h}_{\mathrm{ij}}^{\mathrm{k}, \mathrm{k}+1}=\Delta \mathrm{h}_{\mathrm{ij}}^{\mathrm{k}+1}-(\underbrace{\mathrm{h}_{\mathrm{j}}^{\mathrm{k}}-\mathrm{h}_{\mathrm{i}}^{\mathrm{k}}}_{=\Delta \mathrm{h}_{\mathrm{ij}}^{\mathrm{k}}}) \quad(ب-1 \varepsilon)(1, \mathrm{c}$

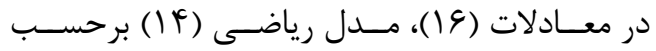
جابهجايى نقاط شبكه نسـبت بـهـ إِكى k ام بازنويسى (1)، برحي

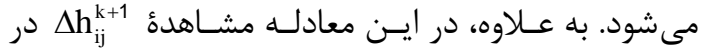

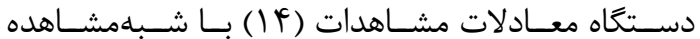

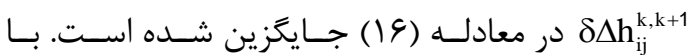

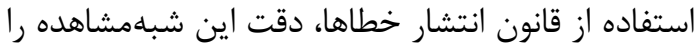
مىتوان با بهرهيرى از اين رابطه محاسبه كرد [9]. رابطه (IV)

$\sigma_{\delta \Delta h_{i j}^{k+1}}^{2}=\sigma_{\Delta h_{i j}^{k+1}}^{2}+\sigma_{\Delta h_{i j}^{k}}^{2}-2 \operatorname{cov}\left(h_{j}^{k}, h_{i}^{k}\right)$

برخلاف دستكاه معادلات (f ( )، معادلات مشـاهدات در دستكاه معادلات (ع) برحسب اخـتلاف مختصـات

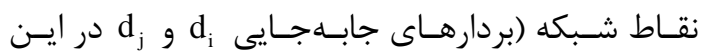
رابطه) فرموله شده است. به ايسن ترتيـب، تغييــر شـكل صلب شبكه در قالب انتقال يكنواخـت نقـاط آن، دوران

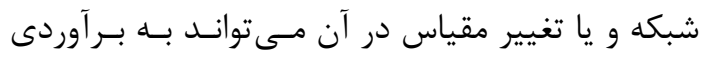

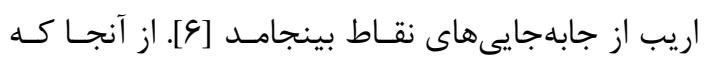

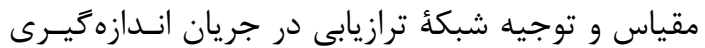

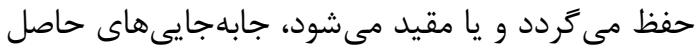

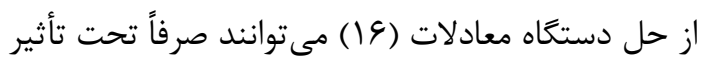
انتقال يكنواخت تمامى نقاط شبكه قرار كيرند. شناسايى نقطه يا نقاطى ثابت در فاصله زمانى بـين ناطين

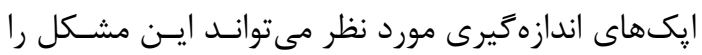




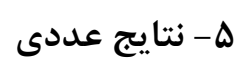

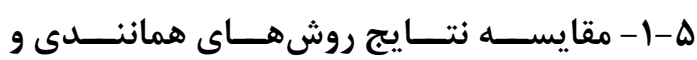
مينيممسازى نرم اL بردار جابه جايـى

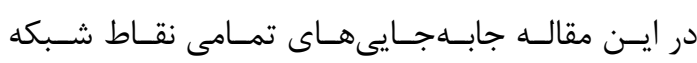

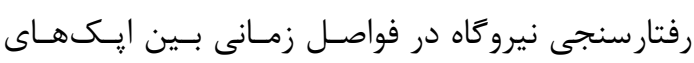

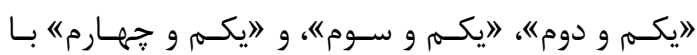

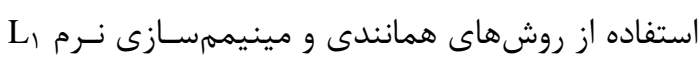
بردار جابهجايى و در سطح اطمينان هو د درصد محاسبه

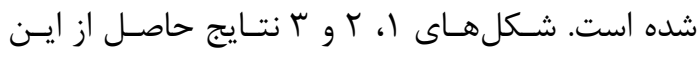

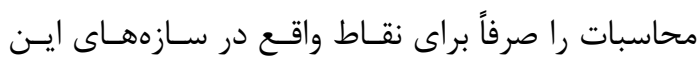

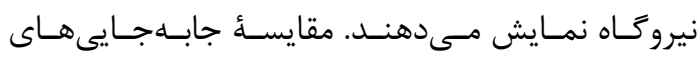
محاسبه شده براى نقاط اين شبكه با فواصـل اطمينــان

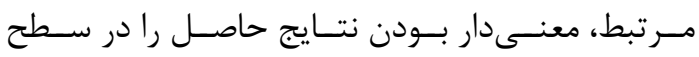
اطمينان ياد شده تأييد مى كند.
رابطه (TI)

$$
\mathbf{Q}_{\hat{\mathbf{d}}}=\left(\mathbf{A}^{T} \mathbf{P A}+\mathbf{W}\right)^{-1} \mathbf{A}^{T} \mathbf{P A}\left(\mathbf{A}^{T} \mathbf{P A}+\mathbf{W}\right)^{-1}
$$

رابطه (Tr)

$$
\hat{\mathbf{v}}=\left[\mathbf{A}\left(\mathbf{A}^{T} \mathbf{P A}+\mathbf{W}\right)^{-1} \mathbf{A}^{T} \mathbf{P}-\mathbf{I}\right] \delta \Delta \mathbf{h}^{\mathrm{k}, \mathrm{k}+1}
$$

$\mathbf{Q}_{\hat{\mathbf{v}}}=\mathbf{A}\left(\mathbf{A}^{T} \mathbf{P A}+\mathbf{W}\right)^{-1} \mathbf{A}^{T} \mathbf{P A}\left(\mathbf{A}^{T} \mathbf{P A}+\mathbf{W}\right)^{-1} \mathbf{A}^{\mathbf{T}}$

$$
-2 \mathbf{A}\left(\mathbf{A}^{T} \mathbf{P A}+\mathbf{W}\right)^{-1} \mathbf{A}^{T}+\mathbf{C}_{\delta \mathbf{A} \mathbf{h}^{k, k+1}}
$$

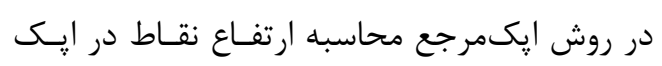

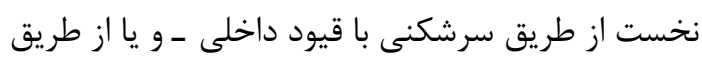
سرشكنى با حداقل قيود ـ امكانيذير است.

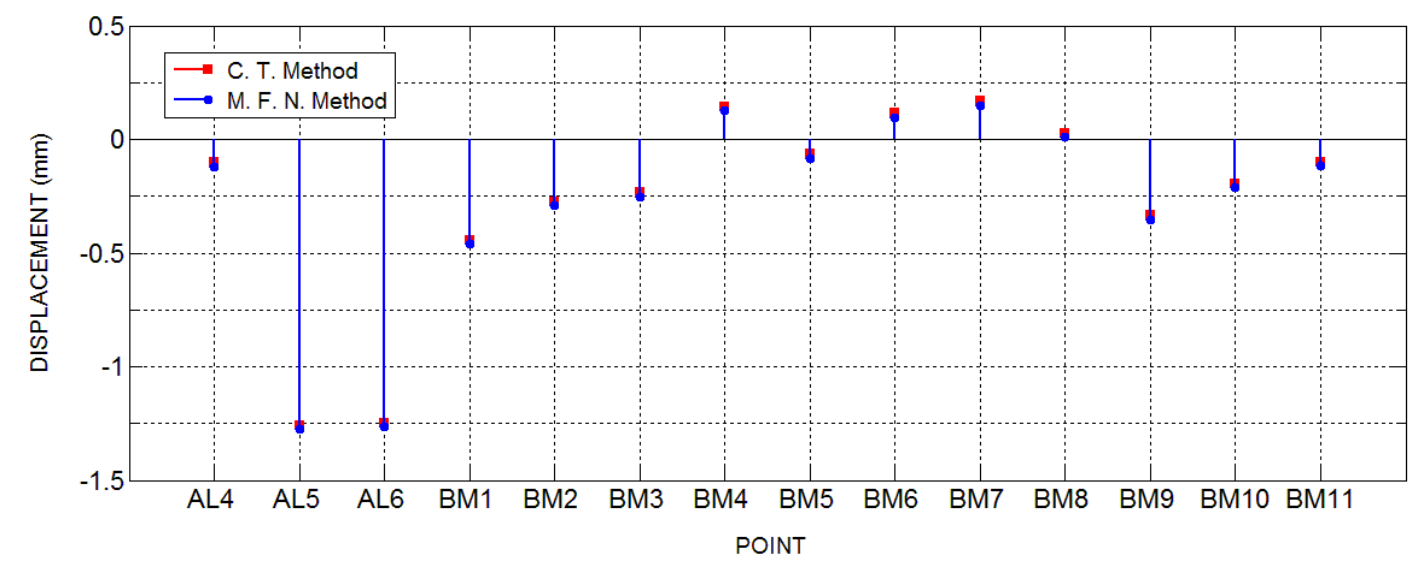

شكل ا. جابهجايى نقاط مرجع بين إِكهاى يكم و دوم حاصل از روشهاى همانندى و مينيممسازى نرم L بردار جابهجايى

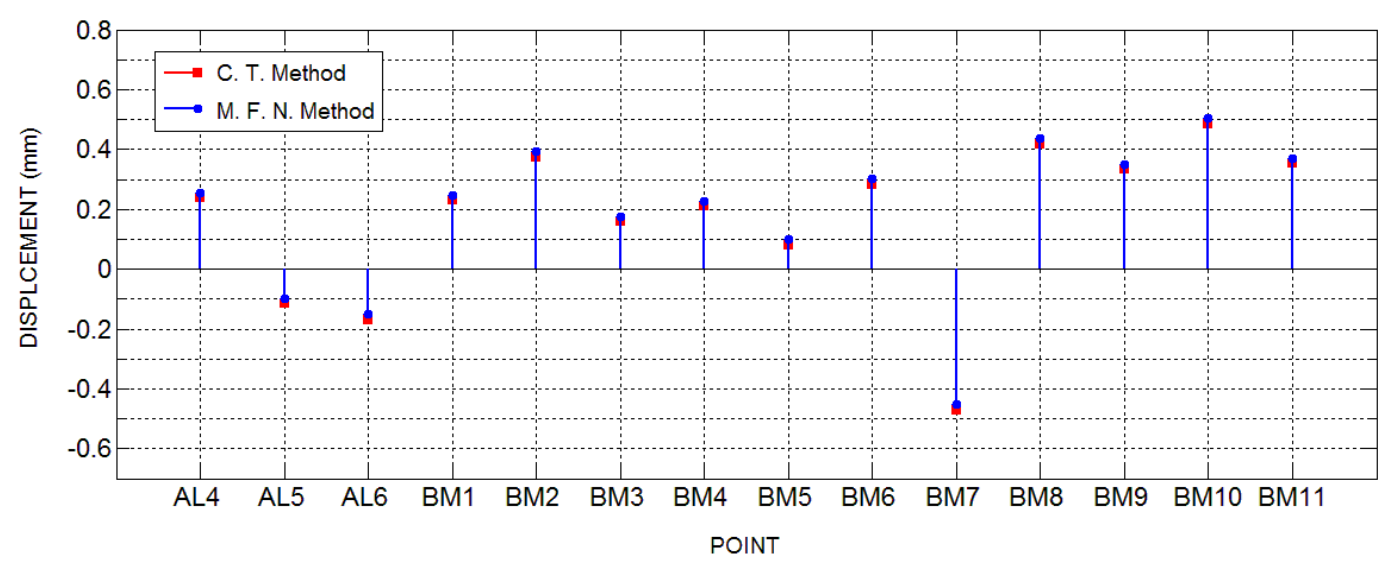

شكل r. جابهجايى نقاط مرجع بين إيكهاى يكم و سوم حاصل از روشهاى همانندى و مينيممسازى نرم Lا بردار جابهجايى 


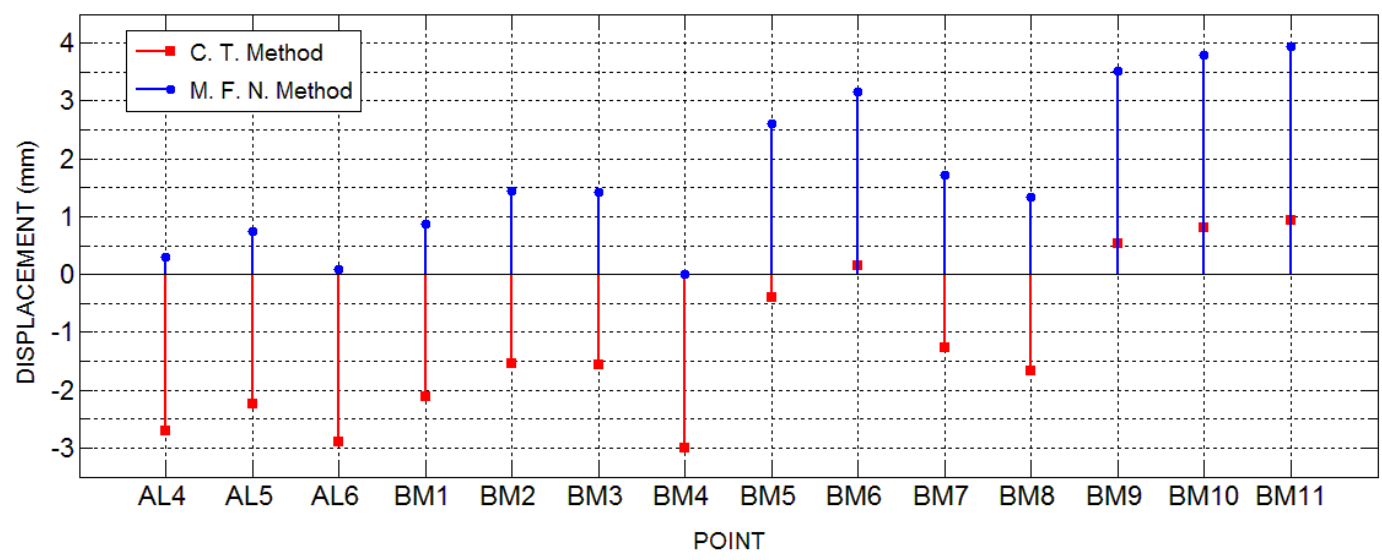

شكل rا. جابهجايى نقاط مرجع بين إيكهاى يكمم و جهارم حاصل از روشهاى همانندى و مينيمهسازى نرم البردار جابهجايى

مورد اسـتفاده بــراى تعيـين بارامترهـاى بايــؤ طراحسى سازهها، رسيدن به برآوردى صحيح از اين بارامترهـا - و

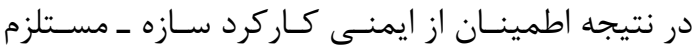

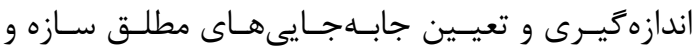

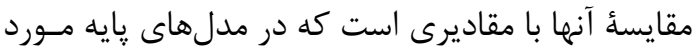
استفاده در فرايند طراحى سـازه هـيشبينسى مسىشـود.

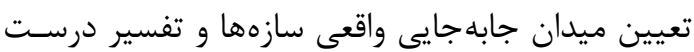

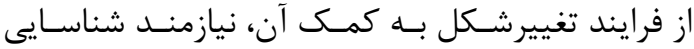
نقاط يايدار شبكه ميكروزئودزى ارتفاعى نيروكَاه اتمسى

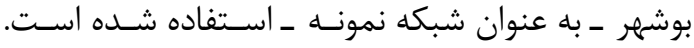
نتايج بهدست آمده از آناليز دادههاى اين شبكه، نشان از لناز

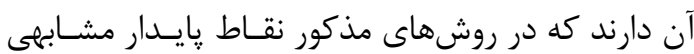

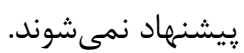

اين موضوع، محاسبهُ جابهجـايى مطلـق نقــاط ايسن

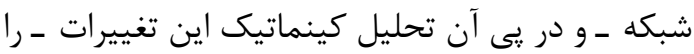
ناممكن مى سازد. اين مشـكل از يـك سـو، و توجـهـ بــهـ

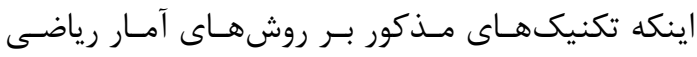

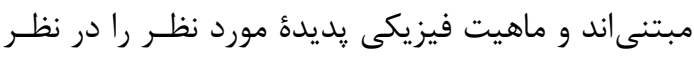

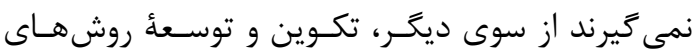

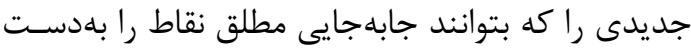
دهند، اجتنابنايذير مىنمايد.

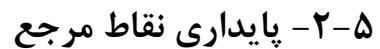

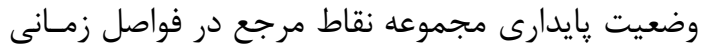

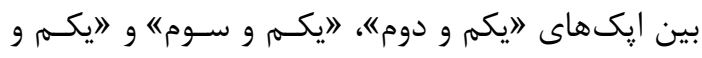

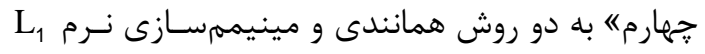

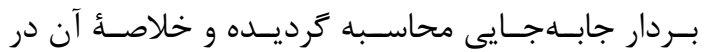
جدول ا درج شده است. بررسى و مقايسـأ ايـن نتـايج

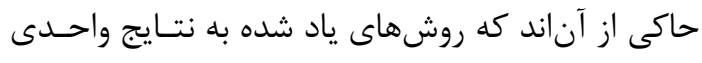

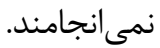

ه-r- - جابهجايى مطلق نقاط به روش إيكمرجع

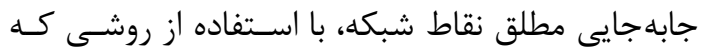

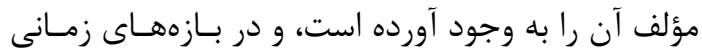

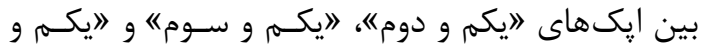

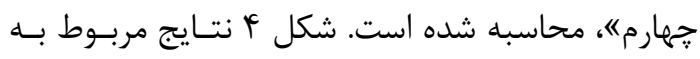

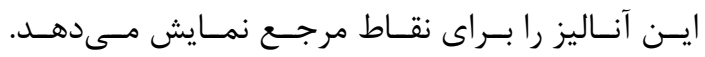

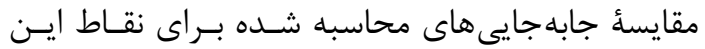

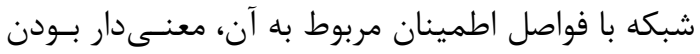

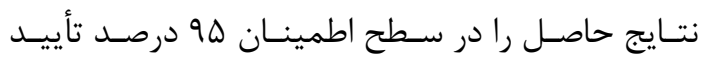
مى كند.

$$
\text { 4- نتيجه }
$$

با توجه به محدوديتهـاى موجـود در روش زئوتكنيـى 


\section{ييشنهاد روشى جديد در آناليز...}

غلامرضا رضايى جاويد و مسعود مشهدى حسينعلى جيدي

جدول ا. نتايج آناليز پايدارى نقاط مرجع در شبكهُ ميكروزئودزى ارتفاعى نيروكاه اتمى بوشهر

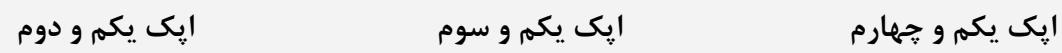

نقاط

\begin{tabular}{l|lllll} 
C. T. M. & M. F. N. M. & C. T. M. & M. F. N. M. & C. T. M. & M. F. N. M.
\end{tabular}

AL4

טايدار

ֶֶ.

טإيدار

טֶايدار

نـاـــــــــ ار

بـايسد ار

AL5

نايايدار

نايايدار

هايدار

هايدار

نايايدار

نايايدار

AL6

نايايدار

نايايدار

ֶايدار

پايدار

نـاِـايسد ار

مبايسد ار

\begin{tabular}{|c|c|c|c|c|c|c|}
\hline BM1 & نايايدار & نإِايدار & هِايدار & هِايدار & نايايدار & نإِايدار \\
\hline BM2 & يقايدار & يقايدار & ي بايدار & يايدار & نايايدار & نايايدار \\
\hline BM3 & هِايدار & هِايدار & لِّا يدار & پِايدار & نايايدار & نإيايدار \\
\hline BM4 & קֶايدار & هايدار & هِايدار & קِايدار & نــا پــــــــد ار & يـايــد ار \\
\hline BM5 & هيايدار & هِيدار & هِايدار & هيايدار & ״ـــــــد ار & نــــــــــد ار \\
\hline BM6 & هِايدار & هايدار & بايدار & هايدار & ״ــايــد ار & نــاِــــــد ار \\
\hline BM7 & هِايدار & هِايدار & نـاِـــــــد ار & رِايـد ار & نايايدار & نإيايدار \\
\hline BM8 & هِايدار & هِيدار & هِايدار & هِايدار & نايايدار & نايايدار \\
\hline BM9 & نايايدار & نايايدار & قِايدار & قِايدار & نإيايدار & نإيايدار \\
\hline BM10 & بـا يــد ار & نـــــــــــار & مֶايدار & پِايدار & نايايدار & نإيايدار \\
\hline BM11 & يَايدار & ي بايدار & ي بايدار & ي بايدار & نايايدار & نإيايدار \\
\hline
\end{tabular}

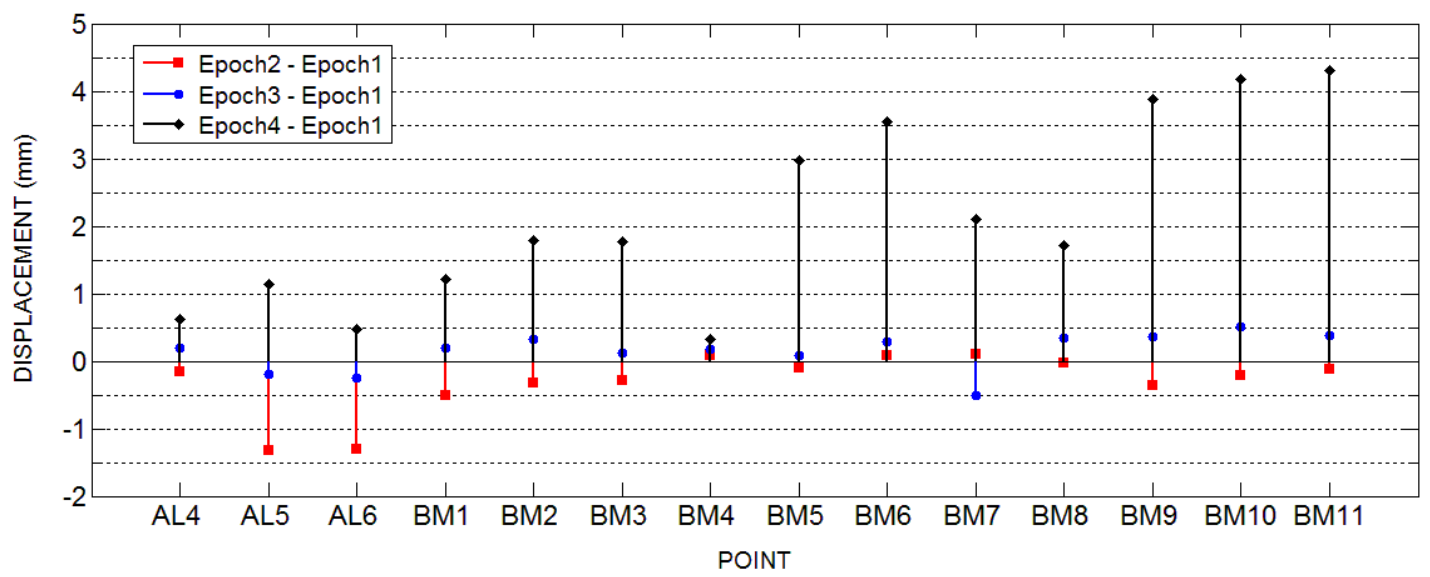

شكل F. جابهجايى مطلق نقاط مرجع شبكه ميكروزئودزى ار تفاعى نيروگاه اتمى بوشهر، با استفاده از روش إيكمرجع 


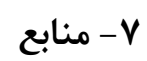

[1] Chen Y.Q., Chrzanowski A. and Secord J. M., 1990. A Strategy for the Analysis of the Stability of Reference Points in Deformation Surveys, CISM Journal ACSGS, 44(2), 141-149.

[2] Chrzanowski A., Chrzanowski A.S., Bond J. and Wilkins R., 2007. Increasing Public and Environmental Safety Through Integrated Monitoring and Analysis of Structural and Ground Deformations, Geomatics Solution Fordisaster Management, 407-426.

[3] Cooper M.A.R., 1987. Control Surveys in Civil Engineering. William Collins Sons, Co.

[4] Krakiwsky E. J., 1975. A Synthesis of Recent Advances in the Method of Least Squares, Canada: The University of New Brunswick.

[5] Kuang, S., 1996. Geodetic Network Analysis and Optimal Design: Concepts and Applications, UK: Sams pubs.

[6] Mikhail E. M., Grace G., 1981. Analysis and adjustment of survey measurements, New york: Van Nostrand Reinhold Inc.

[7] Setan H. and Singh R., 2001. Deformation Analysis of Geodetic Monitoring, Geomatica, 55(3).

[8] Wells D.E. and Krakiwsky E.J., 1971. The Method of Least Squares. Canada: The University of New Brunswick.

$$
\begin{aligned}
& \text { در اين مقاله، روش جديدى براى حل ايـن مشـكل }
\end{aligned}
$$

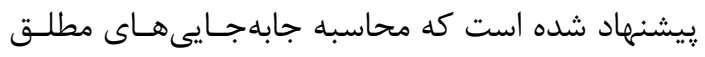

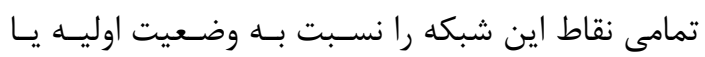

$$
\begin{aligned}
& \text { وضعيت مرجع شبكه امكـان يـذير مسىســازد. منظــور از } \\
& \text { وضعيت اوليه يا مرجع شبكه، ارتفاع موقعيت يا وضعيت } \\
& \text { نقاط آن در نخستين مرحله اندازهگيرى آن است. تنهيـا }
\end{aligned}
$$

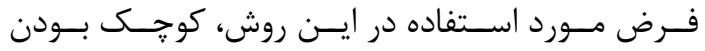

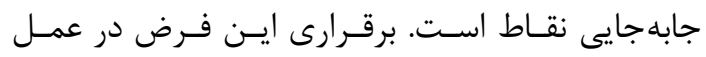

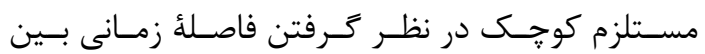

$$
\begin{aligned}
& \text { إيكهاى اندازمخيرى است. } \\
& \text { در فاصلة زمانى إيكهاى اندازهيرى مورد اسـتفاده }
\end{aligned}
$$

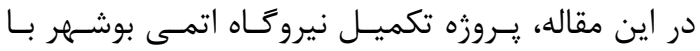

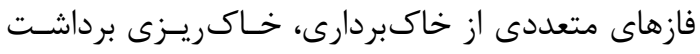

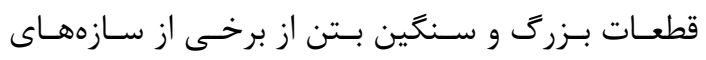

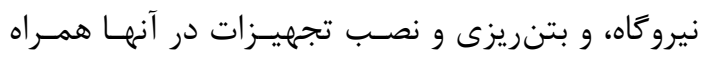

$$
\begin{aligned}
& \text { بوده است. اين موضـوع خـود از يـــ سـو، و در اختيــار } \\
& \text { نداشتن ركورد زمانى دقيقى از بازههاى زمانى مرتبط بـاــا } \\
& \text { هر يك از فعاليتهاى عمرانسى مـذكور از سـوى ديخـر، }
\end{aligned}
$$

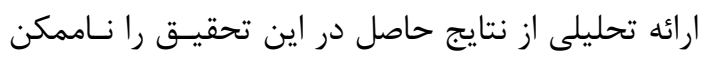

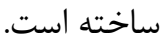




\title{
A New Method for Deformation Analysis of Vertical Networks
}

\author{
Rezaee Javid G.R. ${ }^{1}$, Mashadi Hossainali M.*2
}

1- M.Sc. Student in Geodesy, Faculty of Geodesy \& Geomatics, K.N. Toosi University of Technology

2- Assistant Prof., Faculty of Geodesy \& Geomatics Engineering, K.N. Toosi University of Technology

\begin{abstract}
Analyzing the stability of reference points is a key problem in deformation analysis. The reason is that the instability of these points results in the erroneous interpretation of the deformation process. In this paper, the stability of points in a vertical network has been analyzed, using the given methods of congruency and minimum-making the first norm. Comparison of the obtained results proves that the two methods do not provide a unique solution for the problem. Considering the obtained contrary results and the need for the estimation of the absolute displacements of the network points, a new method has been developed. Using the mentioned method, which is based on the reformulation of the corresponding observation equations, makes possible to compute the absolute displacements of the network points with respect to a reference measurement epoch.
\end{abstract}

Keywords: Deformation Analysis, Congruency Method, Minimum First Norm Method, Reference Epoch Method.

* Correspondence Address: 1346, Valiasr Street, Mirdamad intersection, Tehran, Iran. Tel: 021-88888445 Email: hossainali@kntu.ac.ir 